\title{
Downtown, strip centers, and big-box stores: Mode choice by shopping destination type in Davis, California
}

\author{
Natalie Danielle Popovich \\ University of California at Davis \\ ndpopovich@ucdavis.edu
}

\author{
Susan Handy \\ University of California at Davis \\ slhandy@ucdavis.edu
}

\begin{abstract}
Growing concerns about climate change and traffic congestion are motivating policymakers to find ways to encourage sustainable travel options. In the United States, where 88 percent of shopping trips are made by car, research identifying the factors that influence shopping mode choice can provide insight into ways to divert some of these trips to more sustainable alternatives. This paper aims to better explain the relationship between the built environment and shopping mode choice by examining how mode choice differs for the same individual across three different types of shopping destinations-downtown, strip center, and big box-in Davis, California. We conducted two cross-sectional online surveys in 2009 and 2010 with a total of 2043 respondents that asked questions about recent shopping. To understand the factors influencing mode choice at these three shopping destination types, we estimate binary logit models for choosing to use an active travel mode (bike or walk) to shop. Our results suggest that while distinct factors influence mode choice at the different destination types, simple infrastructure changes to the destination are not enough to encourage mode shift. Distance to shopping destinations and enjoying bicycling are the primary determinants of choosing active travel modes, while sociodemographic characteristics play a smaller role.
\end{abstract}

\section{Article history:}

Received: January 31, 2014

Received in revised form:

September 12, 2014

Accepted: November 19,

2014

Available online: June 1,

2015

\section{Introduction}

Growing concerns about climate change and traffic congestion are motivating policymakers to find ways to encourage sustainable travel options. While there has been significant research on the impact of the built environment on commute travel choices (Rodriguez and Joo 2004; Cervero and Gorham 1995; Ewing and Cervero 2010; Shiftan and Barlach 2002), only a few studies have considered how the built environment influences shopping mode choice (Jiao, Moudon, and Drewnowski 2011; Clifton et al. 2013; Meisel 2010; O'Connor, Nix, Bradshaw, and Shiel 2011). In the United States, where 88 percent of shopping trips are made by car (Santos et al. 2011), such research can help identify ways to divert some of these trips to more sustainable modes. While the possibility of shifting modes for shopping travel through land-use planning and infrastructure investments has achieved much support from proponents of new urbanism and smart growth, such changes are not always applicable-especially in the short term - to suburban settings, where land-use planning has historically revolved around the automobile. In places where changes in land-use patterns and to the transportation network are prohibitively expensive

Copyright 2015 Natalie Danielle Popovich \& Susan Handy

http://dx.doi.org/10.5198/jtlu.2015.739

ISSN: 1938-7849 | Licensed under the Creative Commons Attribution - Noncommercial License 3.0

The Journal of Transport and Land Use is the official journal of the World Society for Transport and Land Use (WSTLUR) and is published and sponsored by the University of Minnesota Center for Transportation Studies. This paper is also published with sponsorship from WSTLUR and the Institutes of Transportation Studies at the University of California, Davis, and the University of California, Berkeley. 
and not viable options in the short run, it is worth considering whether changes to the built environment at the destination can encourage travel modes other than driving.

In the United States, traditional downtowns were designed for pedestrians who generally arrived by streetcar or bus. Following World War II, retail activity increasingly shifted to suburban shopping malls, conveniently located on major arterials and providing ample free parking for customers arriving by car. Starting in the 1980s, "big box" stores such as Walmart and Target offered customers easy one-stop shopping but were also designed for car access. It is not surprising then that most shopping trips in the United States are by car. In addition, for many decades, priority for road space and on-street parking has gone to cars, adding to the attractiveness of driving to shopping destinations. However, communities are increasingly recognizing the importance of other modes in bringing customers to local businesses. Understanding what motivates individuals to select different travel modes to different shopping destinations is important for determining effective ways to reduce vehicle travel and promote the alternatives.

This study identifies how factors influencing travel mode differ across three types of shopping destinations in Davis, California: downtown, strip centers, and a big-box store. We analyze data from two cross-sectional online surveys conducted in 2009 and 2010 that asked a total of 2043 residents about recent shopping trips in Davis. First, we examine differences between shoppers using different modes with respect to socio-demographic and attitudinal characteristics. Second, we examine how factors influencing travel mode differ across shopping destination types. We find that perceptions of the built environment are mostly insignificant for all destination types. Distance to the shopping destination and bicycling enjoyment are the primary determinants of choosing active travel modes, while socio-demographic characteristics play a smaller role. These results suggest that while distinct environmental factors influence mode choice at the destination types, simple infrastructure changes at the destination are not enough to encourage mode shift. Rather a host of environmental factors are important in determining mode, such as bicycle lanes, the connection between bike paths and shopping centers, shade trees along the routes, and other characteristics that cannot be observed when looking only at the destination.

\section{Conceptual framework}

A number of studies shed some light on the specific connection between the built environment and mode choice for shopping trips (Handy 1996; Zang 2004; Frank and Pivo 1994; Clifton et al. 2013; Schneider and Pande 2012). Land-use patterns determine proximity to shopping destinations and street networks determine travel times; design influences the attractiveness of different destinations, while infrastructure quality influences the comfort, safety, and convenience of getting to each (Handy 1996). Different types of shopping destinations offer different experiences for shoppers in terms of ease of parking, store size, numbers of stores, and access between stores, as well as price, quality and diversity of items available, personal interactions, and other amenities.

While land-use patterns and the current allocation of road space in the United States support driving, appropriate design of the built environment at trip destinations can encourage the use of active modes. Denser placement of storefronts, for example, can increase active travel between shopping destinations. In the San Francisco Bay Area, shoppers were twice as likely to walk between shopping destinations along suburban main streets (i.e., downtown) as between shopping destinations along suburban thoroughfares (Schneider and Pande 2012). Similarly, pedestrians in Austin, Texas, were significantly more likely to walk to local shopping destinations if they felt comfortable walking around the shopping destination once they arrived (Handy and Clifton 2001). A number of studies examining the impact of bicycle and pedestrian infrastructure at shopping destinations on mode choice suggest that providing designated bicycle parking areas is an effective way to increase bike and pedestrian mode shares. A downtown shop-

ping corridor with bike lanes and parking areas in Dublin, Ireland, had three times as many shoppers arriving by bike as a similar street without bicycle infrastructure (O'Connor et al. 2011). The same study 
found that-relative to shoppers arriving by all other modes-cyclists reported the lowest monthly spending amounts per capita on the street without cycling infrastructure, but the highest spending amounts on the street with cycling infrastructure (O'Connor et al. 2011). Business owners in Portland, Oregon, perceived that the share of their customers arriving by bicycle increased (or at the very least stayed the same) when the city installed designated bicycle parking areas within a half-block of their business (Meisel 2010). Clifton et al. (2013) confirmed these perceptions in a more recent study that found that bicycle mode shares at shopping establishments were correlated with the presence of bike parking and corrals. The provision of vehicle parking, on the other hand, can work against encouraging active travel modes to shop. In Seattle, grocery stores with more ground-level parking had more customers arriving by car, even when controlling for household vehicle access and distance to grocery store (Jiao et al. 2011).

While the built environment influences the choice set of modes available to an individual, past research indicates that attitudes play a role in mode choice, potentially even overwhelming the effect of the built environment (Schwanen and Mokhtarian 2005; Heinen, Maat, and Wee 2011; Handy and Clifton 2001), though only two of these studies included bicycling as a mode choice (Heinen, Maat, and Wee 2011; Handy and Clifton 2001). In Sweden, individuals who reported higher rates of recycling and composting were more likely to choose the train over the bus, but not significantly less likely to drive, suggesting that while general environmentally friendly tendencies may be correlated with certain mode choices, attitudes specific to the environmental aspects of different modes may be better predictors of mode choice (Vredin Johansson, Heldt, and Johansson 2006). In the Netherlands, cyclists who commuted longer distances had more positive attitudes toward bicycling than those with shorter commutes, suggesting that pro-bicycling attitudes can overpower some of the inconveniences of the built environment (Heinen, Maat, and Wee 2011). Although shorter trip distances make active travel options more feasible, the availability of alternatives is not necessarily enough to induce mode shift in the United States. While Austin residents reportedly valued the availability of nearby shopping options, their availability alone was not sufficient to divert automobile trips to other modes (Handy and Clifton 2001). Attitudes can thus work for or against the use of active modes.

A more thorough understanding of the factors that influence an individual's shopping mode choice can help business owners and policymakers make more informed decisions for their communities. This paper aims to contribute to the growing body of research on how different types of shopping destinations influence travel mode. Rather than using observed built environment characteristics, we include perceptions of the built environment, which allows us to disentangle the effect of the actual built environment from its effect as perceived by individuals. Past studies on shopping mode choice have considered either shopping trips for any purpose (Transportation Alternatives 2012, Bent and Singa 2009, O'Connor et al. 2011) or a specific trip purpose, such as groceries or convenience items (Clifton, Morrissey, and Ritter 2012; Jiao, Moudon, and Drewnowski 2011) at a single point in time. This analysis expands on previous research by considering mode choice for the same type of shopping—retail—across three different types of shopping destinations.

\section{$3 \quad$ Methods}

3.1 Setting

Davis is an unusual setting in which to examine the connection between mode choice and shopping destination type owing to its geographic isolation, land-use patterns, and cycling culture. Davis is well known for having the highest share of workers usually commuting by bicycle in the country at 19.1 percent (American Community Survey 2012). In addition to a mild climate and flat topography, the city 
boasts over 80 kilometers (50 miles) of on-street bike lanes and over 80 kilometers (50 miles) of off-street bike paths in an area of roughly 16 square kilometers (10 square miles) (Buehler and Handy 2008).

Land-use patterns also help to support bicycling and walking for shopping trips. Densities throughout Davis are relatively uniform, and the city is relatively compact, roughly 8 kilometers ( 5 miles) east to west and 4.8 kilometers ( 3 miles) north to south. Thus, nearly all residents are within 4.8 kilometers ( 3 miles) of downtown. Each of the five districts in Davis (central, north, south, east, and west) has one or more neighborhood strip centers that are easily accessed by bicycle, walking, or transit (Figure 1), although the shopping centers differ with respect to access, size, and parking, as summarized in Table 1. Until the mid-2000s, Davis restricted the size of stores to no more than 3251 square meters (35,000 square feet). In 2009, a Target store, the first big-box store in Davis, opened at the eastern edge of the city. Importantly, Davis is surrounded by agricultural land, so that the nearest neighboring community-and the next nearest big box store-is 16 kilometers (10 miles) away.

Table 1: Characteristics of shopping destination types

\begin{tabular}{llll}
\hline & Downtown & Strip Center & Target (Big Box) \\
\hline Building setbacks & Minimal & Large & Larger than store area \\
& $185-2,322 \mathrm{sq} \mathrm{m}$ & Max 3,251 sq m & $12,728 \mathrm{sq} \mathrm{m}$ \\
Area of retail space & $(2,000-25,000 \mathrm{sq} \mathrm{ft})$ & $(35,000 \mathrm{sq} \mathrm{ft})$ & $(137,000 \mathrm{sq} \mathrm{ft})$ \\
Average number of shops per block & $8-12$ & $4-10$ & 1 \\
Car parking & Usually free, limited time, & Free, unlimited, park- & Free, unlimited, parking \\
& on-street & ing lots & lots \\
Bicycle parking & $10-30$ per block & $4-20$ per center & -25 spaces \\
& 7 bus lines, 7 a.m.-8 p.m. & Varies, 1-4 bus lines, 7 & One line, weekends \\
Transit access & weekdays, 9 a.m.-5 p.m. & a.m.-8 p.m. weekdays, & only, 9-5 p.m., one bus \\
& weekends & 9 a.m.-5 p.m. weekends & per hour \\
\hline
\end{tabular}

Ample free vehicle parking is available at all shopping destinations outside of downtown. In the downtown area, on-street parking is free with a two-hour limit Monday through Saturday and all day on Sunday. Two parking garages provide free parking for up to four hours and one metered lot allows up to four hours of parking for $\$ 1$ per hour. Downtown shoppers may be inconvenienced by having to move their vehicles after two hours, but they are sure to find a place to park at no cost. At least one bus line goes to each shopping destination, with downtown being the best served by transit. Buses do not travel to Target on weekdays. A one-way bus fare is $\$ 1$ to anywhere in the city, but undergraduate students can ride the bus for free. 


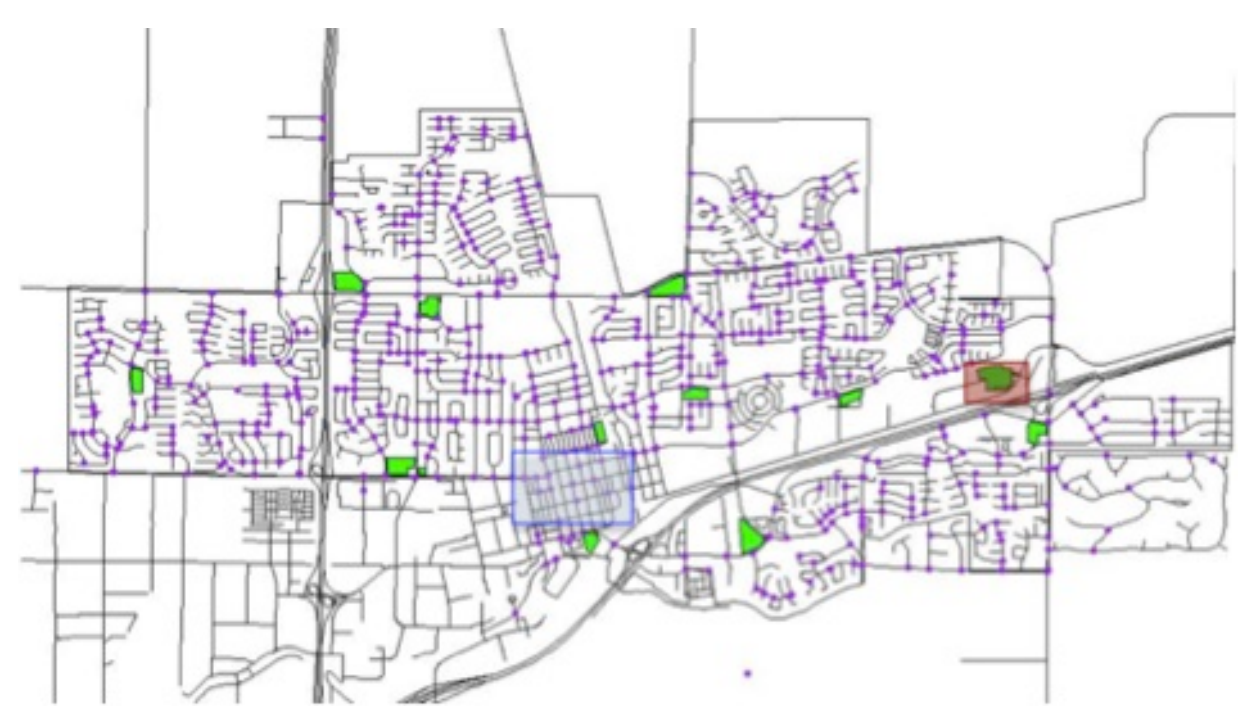

Figure 1: Shopping centers (green), downtown (blue), Target (red), and residential locations of survey respondents (purple)

\subsection{Data}

The data analyzed here are from two online surveys of Davis residents, one administered in September 2009 and a second one administered in October 2010, as described in Lovejoy et al. (2013). The repeated cross-sectional surveys were designed to measure changes in shopping behavior before and after Target opened in October 2009. In each year, letters were sent to a random sample of 5000 Davis residents inviting the recipient to visit a website to complete the online survey or to contact the researchers for a paper version if they preferred. As an incentive to participate, respondents were given the option of entering a drawing for five $\$ 100$ cash prizes. Reminder postcards were sent to all potential respondents a week later. The response rate was 20.4 percent, yielding a combined sample size of 2043 respondents. The sample in this analysis includes all individuals who indicated that they had shopped at least once in the past year at one or more of the three shopping destinations and reported the mode they had used to get there, resulting in a total of 1627 individuals. Table 2 compares standard socio-demographic characteristics of the sample to that of the entire population of Davis.

Table 2: Demographic characteristics of sample compared to Davis

\begin{tabular}{lcc}
\hline & & \multicolumn{2}{c}{ Census Data for Davis } \\
& Sample & (2010) \\
\hline $\mathrm{N}$ & 1627 & 65,622 \\
Mean age of adults ${ }^{1}$ & 51 & 38.4 \\
Female & $53.8 \%$ & $52.5 \%$ \\
Mean household income & $\$ 89,843$ & $\$ 81,863$ \\
Education (if over 25) & & \\
High school or less & $2 \%$ & $12 \%$ \\
Some college & $9 \%$ & $14 \%$ \\
Associate's degree & $5 \%$ & $5 \%$ \\
Bachelor's degree & $35 \%$ & $30 \%$ \\
Graduate degree(s) & $50 \%$ & $39 \%$ \\
\hline
\end{tabular}


The sample as a whole is much older than the adult Davis population, given that college students are underrepresented due to the sampling method (as described in more detail in Lovejoy et al. 2013). The sample also has higher-than-average income and education levels and over-represents women. Given that, on average, women in Davis are less likely than men to bike to work (American Community Survey 2012; Driller 2013), the results reported here probably underestimate the bicycle mode share for shopping trips. The limited student representation further underestimates the bicycle mode share. Age, however, is not a significant determinant of bicycling in the sample, and therefore the higher average age should not have a significant impact on the interpretation of these results.

This paper uses these data to explore how mode choice differs by type of shopping destination with respect to socio-demographic characteristics, perceptions of the built environment, and individual attitudes toward travel and the environment. Modeling the mode choice for shopping trips across multiple destinations allows us to compare the relative impacts of socio-demographic characteristics, attitudes, and perceptions of the built environment for each destination type. The survey asked respondents about their most recent shopping trip to downtown Davis, Target (big box), and strip centers in Davis, so that while we know the respondent's most recent mode choice to each destination type, we do not know how often the respondent uses this mode to get to each destination. The survey defined downtown as bounded by particular streets and showed a map of the area; shopping destinations outside of this region, but still within Davis city limits, were considered in a separate category, which we refer to as strip centers. For downtown and other shopping destinations (including Target in the 2010 survey), the survey asked respondents about what types of items they had shopped for (in the last year) at that destination, the typical frequency with which they shop at that destination, and for the most recent occasion, a series of other questions, including what mode they had used to get there and the items purchased or browsed for. The 17 categories of items included in the survey were identified as the sort offered at Target (Table 3). The survey asked respondents for their perceptions of each shopping destination with respect to arriving by different modes and parking there, for both bicycles and cars. The survey also included questions to measure respondents' attitudes about shopping, time use, travel modes, and environmental issues, which previous research has shown to have significant impacts on mode choice, such as Vredin Johansson et al. (2006). The survey concluded with questions capturing socio-demographic characteristics of individuals and their households and the cross-streets near where they lived. 
Table 3: Types of items included in the scope of shopping ${ }^{1}$

\begin{tabular}{ll}
\hline Category & Relevant items \\
\hline Bedding and bath items & Sheets, pillows, bedspreads, towels, shower curtains, soap dishes, etc. \\
Books or electronic media & Books, DVDs, mp3s, video games \\
Cleaning supplies & Mops, sponges, detergent, cleaner, etc. \\
Clothing for adults & Clothes, shoes, accessories for women and/or men \\
Clothing for children & Clothes, shoes, accessories for children and babies \\
Electronics & Phones, cameras, audio equipment, video game consoles, and related items \\
Furniture & Tables, chairs, sofas, bookcases, lamps, etc. \\
Garden supplies & Plants, pots, potting soil, plant food, etc. \\
Hardware & Hand tools, hooks, knobs and pulls, etc. \\
Home décor & Curtains, rugs, pictures frames, vases, etc. \\
Office, school, or art supplies & Paper, notebooks, pens, wrapping paper, scrapbooking supplies, etc. \\
Patio items & Patio furniture, barbecues, umbrellas, etc. \\
Small appliances & Microwaves, blenders, irons, vacuum cleaners, etc. \\
Sporting goods & Sports equipment, fitness equipment, camping equipment, bicycles, etc. \\
Storage and organization & Storage boxes or baskets, closet systems, shelving, etc. \\
Toiletries or cosmetics & Shampoo, soap, toothpaste, make-up, etc. \\
Toys or games & Character toys, stuffed animals, board games, puzzles, playhouses, etc. \\
\hline${ }^{1}$ Respondents were asked, "Have you shopped at a store in [destination] for any of the following items within the last year (Remember \\
we mean not just purchasing, but also browsing or gathering information about an item)
\end{tabular}

We conduct two sets of analyses with these data to explore how mode choice varies by shopping destination type. First, we focus on differences across the destination types. We examine differences across travel modes with respect to socio-demographic characteristics and attitudes, where respondents are categorized by the mode that they reported using to get to their shopping destination on their most recent shopping trip. We compare perceptions of the built environment across modes and shopping destination types and then use binary logit models to identify key factors influencing the choice to use active travel modes (bike or walk) to shop at each of the three destination types, including socio-demographic characteristics, perceptions of the built environment, and attitudes. For the binary logit models, data from the two survey years are pooled (note that data for Target are from the 2010 survey only). Second, we explore factors associated with greater individual use of bicycling for shopping trips. We estimate ordered logit models for how many of the most recent shopping trips to each of the three destination types an individual completed by bicycle, ranging from none to all three trips (i.e. the respondent bicycled on her or his most recent shopping trip to each of the three destination types: Target, downtown, and a strip center). We present summary statistics for four mode categories - car, bike, transit, and walk-though transit users are not included in the models owing to the small sample size. Individuals who reported driving to their shopping destination or being given a ride are included in the car category. A handful of participants listed "other" for their mode and are excluded from this analysis. Data were analyzed using the statistical software package $\mathrm{R}$.

In addition to standard socio-demographic variables, we include in the models the number of years lived in Davis, student status, car access, employment status, work location, and distance from the respondent's home to the respective shopping destination. Level of car access was defined by the response to the question, "How much of the time do you have access to a car, either as a driver or passenger, when you are shopping for the listed products, whether you actually choose to use it or not?" and was measured on 
a six-point scale from "Never" to "Whenever I want." Level of car access and distance to store are expected to be negatively associated with bicycling and walking, while individuals who work (and live) in Davis are expected to bike or walk more frequently to shop at all three destination types. Importantly, 90.3 percent of this sample's respondents indicated they have access to a car at all times, and 94 percent of respondents have access at least 80 percent of the time.

To evaluate the importance of individual perceptions about travel modes as well as to compare observed characteristics to such perceptions, we include five variables about the perceptions of the built environment with respect to the convenience of using different modes to shop. For each destination, respondents were asked, "In general, how would you evaluate shopping in [shopping destination] with respect to the following characteristics? Please rate each characteristic on a scale from 1 to 5 as indicated." The five characteristics include: driving there, parking there, walking there, biking there, and quality/availability of bike parking, with responses on a scale from "difficult" [1] to "easy" [5], which were adjusted to a scale from [-2] to [2] for modeling purposes. We expect perceptions of the convenience of different travel modes to differ by shopping destination type and that destinations with more positive perceptions of biking and walking convenience to correspond to higher active travel mode shares. We expect perceived bicycling convenience to be positively correlated with using active travel modes and driving and parking convenience to have the opposite effect. Walking convenience most likely reflects distance to the store and thus may not be a very helpful measure of pedestrian accommodations at the destination.

To facilitate model development, we grouped attitudinal questions into factors and calculated the following four factor scores by taking the mean response for each group of questions: enjoys biking, eco concern, prefers to buy local, and pro-Target (Table 4). Responses to these questions were on a scale from Strongly Disagree [-2] to Strongly Agree [2]. We then performed a confirmatory factor analysis to ensure that these conceptually generated factors were appropriate to the data. The first factor is expected to be positively related to bicycling and the second to both bicycling and walking. The factors for prefers to buy local and pro-Target are not expected to have a direct influence on mode choice, though they might be correlated with a bundle of attitudes associated with more and less bicycling, respectively. 
Table 4: Description of factor variables in models

\begin{tabular}{|c|c|c|c|}
\hline $\begin{array}{l}\text { Factor } \\
\text { Variable }\end{array}$ & Statement as Appearing on Survey & Mean & $\begin{array}{l}\text { Factor } \\
\text { Mean }\end{array}$ \\
\hline \multirow{3}{*}{$\begin{array}{l}\text { Enjoys } \\
\text { biking }\end{array}$} & Carrying purchases home when walking or bicycling is a hassle. & 0.55 & 0.2 \\
\hline & Whenever possible, I prefer to walk or bike rather than drive. & 0.22 & - \\
\hline & I like riding a bike. & 0.84 & - \\
\hline \multirow{2}{*}{$\begin{array}{l}\text { Eco } \\
\text { concern }\end{array}$} & $\begin{array}{l}\text { I am willing to pay a little more to use a hybrid or other clean-fuel vehicle to reduce } \\
\text { greenhouse gas emissions and improve air quality. }\end{array}$ & 0.44 & 0.12 \\
\hline & We should raise the price of gasoline to reduce congestion and air pollution. & -0.19 & - \\
\hline \multirow{4}{*}{$\begin{array}{l}\text { Prefers to } \\
\text { buy local }\end{array}$} & $\begin{array}{l}\text { I am willing to pay a little more to buy from locally owned businesses rather than } \\
\text { national chains. }\end{array}$ & 0.27 & 0.18 \\
\hline & It is important to me to get the lowest prices when I buy things. & 0.63 & - \\
\hline & It's important to shop in Davis to keep the tax revenues here. & 0.71 & - \\
\hline & When I need to buy something, I usually prefer to get it at the closest store possible. & 0.38 & - \\
\hline \multirow{4}{*}{ Pro-Target } & $\begin{array}{l}\text { National chain stores do a lot of good by increasing product diversity and keeping } \\
\text { costs down. }\end{array}$ & 0.44 & 0.47 \\
\hline & It was a good decision to allow a Target store in Davis. & 0.75 & - \\
\hline & $\begin{array}{l}\text { I am concerned about the effect that the Target store in Davis has had on downtown Da- } \\
\text { vis. }\end{array}$ & -0.11 & - \\
\hline & The Target store in Davis has had a negative impact on neighborhoods in east Davis. & -0.54 & - \\
\hline
\end{tabular}

\subsection{Limitations}

The data collection process and the survey questions have a number of limitations. First, because the primary purpose of this study was to obtain information on how driving behavior changed after Target opened in Davis, the survey questions asked only about shopping for goods in the categories of items available at Target (Table 3). Second, we examine only the mode used for the most recent shopping trip to each destination although this mode choice may not be representative of the individual's regular travel behavior. Third, we do not estimate full mode choice models in which the chosen mode and the unchosen modes are represented for each individual because of the small number of respondents who reported walking or taking transit to shopping destinations. Fourth, questions about perceptions of the built environment were open to interpretation and-with the exception of bicycle and car parking-cannot be linked to specific structural characteristics or types of infrastructure.

\section{$4 \quad$ Results}

The mode shares for each shopping destination are displayed in Table 5. The last column compares the shopping mode share for this sample to the commute mode shares for the city of Davis as estimated in the American Community Survey (ACS); no independent estimates of shopping mode share for Davis are available. 
Table 5: Mode shares by shopping destination type

\begin{tabular}{lrcccc}
\hline & Downtown & Strip Centers & Target & $\begin{array}{c}\text { Davis Commuting } \\
\text { (ACS 2010, three-year) }\end{array}$ \\
\hline$N$ & & 1,519 & 1,372 & 662 & 25,927 \\
Mode Split & Car & $82.3 \%$ & $82.5 \%$ & $93.7 \%$ & $77.9 \%$ \\
& Transit & $0.7 \%$ & $0.8 \%$ & $0.6 \%$ & $8.6 \%$ \\
& Bike & $12.3 \%$ & $10.8 \%$ & $4.5 \%$ & $22.7 \%$ \\
& Walk & $4.7 \%$ & $5.8 \%$ & $1.2 \%$ & $3.1 \%$ \\
\hline
\end{tabular}

${ }^{1}$ These figures exclude individuals that worked from home or selected "other" for mode to work in the ACS data. Numbers do not sum to 100 percent because the ACS data includes telecommuting and taxi as commute modes.

Respondents in our sample are more likely to drive to shopping destinations than Davis workers are to drive to their jobs, which could be explained in part by the low share of students and male respondents in the sample, but also by the fact that many who commute by non-auto modes use a car for shopping so as to be able to carry purchases home conveniently. Downtown has the highest bike mode share, strip centers the highest walk mode share, and Target the highest driving mode share. This pattern might be indicative of the relative inconvenience of parking downtown and land-use patterns that increase the likelihood of living within walking distance of a neighborhood strip center.

\subsection{Differences across shopping destinations}

Table 6 displays the modes used by individuals to arrive at different destination pairs. If all respondents used just one mode to travel to all three destinations, only cells along the diagonal would have nonzero values and the selected travel mode would be best explained by individual preferences. However, because many individuals used multiple modes, models can help tease out the differences between the destination types that affect mode choice.

Individuals who drove downtown were the least likely to use another mode of travel when shopping elsewhere. The few transit users in the sample were also unlikely to change modes for any shopping trips, suggesting that these individuals are captive to transit. Respondents who bicycle are likely to use other modes as well. Those who bicycled to downtown were about equally likely to bike to other destinations as to drive. Most individuals who walked downtown did not walk to shop at other destinations, which is likely because they live close to downtown but not to other destinations. Most residents in Davis have access to both bicycles and cars, and thus we expect the relative ease of using each mode to be an important determinant of shopping mode choice. 
Table 6: Number of individuals using each mode to each shopping destination

\begin{tabular}{r|ccccc}
\hline & \multicolumn{5}{|c}{ Mode to Strip Center } \\
Mode to Downtown & Car & Transit & Bike & Walk & $N$ \\
Car & 474 & 1 & 28 & 22 & 525 \\
Transit & 1 & 0 & 0 & 0 & 1 \\
Bike & 31 & 0 & 38 & 5 & 74 \\
Walk & 18 & 1 & 4 & 6 & 29 \\
\hline Mode to Downtown & Car & Transit & Bike & Walk & $N$ \\
Car & 574 & 2 & 10 & 7 & 593 \\
Transit & 2 & 4 & 0 & 0 & 6 \\
Bike & 62 & 0 & 20 & 0 & 93 \\
Walk & 30 & 1 & 2 & 2 & 38 \\
\hline Mode to Strip Center & Car & Transit & Bike & Walk & $N$ \\
Car & 485 & 0 & 13 & 4 & 502 \\
Transit & 2 & 0 & 0 & 0 & 2 \\
Bike & 50 & 0 & 19 & 0 & 69 \\
Walk & 27 & 1 & 0 & 1 & 29
\end{tabular}

${ }^{1}$ Cell values represent the number of individuals who used each mode, e.g., individuals along the diagonal used the same mode to get to both destinations.

\subsubsection{Characteristics of shoppers by mode and destination type}

Socio-demographic characteristics of the sample differ across shopping destination type and mode (Table 7). Motorists are remarkably similar across all destinations. Cyclists to Target are generally older and wealthier than those to other destinations. Pedestrians are oldest downtown. There are too few transit users to make meaningful distinctions across destinations. Transit users, on average, have the lowest incomes and education levels and highest average age for all destination types. Drivers and cyclists have higher incomes than pedestrians. For downtown shoppers, active travelers are younger than transit and car users. Women are more likely than men to take the bus or walk, and less likely to bike, though not significantly so to downtown. None of the standard socio-demographic variables are significantly different across modes at Target, suggesting that the individuals who bike or walk to Target do not stand out as different from the typical cross-section of Davis residents. 
Table 7: Socio-demographic characteristics of shoppers by mode and shopping destination type

\begin{tabular}{|c|c|c|c|c|c|}
\hline \multicolumn{6}{|c|}{ Downtown } \\
\hline & Car & Transit & Bike & Walk & p-value ${ }^{3}$ \\
\hline $\mathrm{N}$ & 1,250 & 11 & 187 & 71 & - \\
\hline Mean age & 51.9 & 53.5 & 45.1 & 48.0 & 0.000 \\
\hline Female & $53.7 \%$ & $81.8 \%$ & $48.7 \%$ & $63.4 \%$ & 0.044 \\
\hline Mean household income ${ }^{1}$ & $\$ 94,976$ & $\$ 43,182$ & $\$ 76,096$ & $\$ 72,570$ & 0.000 \\
\hline Education $^{2}$ & & & & & 0.266 \\
\hline High school or less & $1.3 \%$ & $11.1 \%$ & $0 \%$ & $2.9 \%$ & - \\
\hline Some college & $7.7 \%$ & $11.1 \%$ & $7.4 \%$ & $4.3 \%$ & - \\
\hline Associate's degree & $4.3 \%$ & $11.1 \%$ & $5.7 \%$ & $2.9 \%$ & - \\
\hline Bachelor's degree & $36.0 \%$ & $22.2 \%$ & $33.5 \%$ & $29.0 \%$ & - \\
\hline Graduate degree(s) & $50.8 \%$ & $44.4 \%$ & $53.4 \%$ & $60.9 \%$ & - \\
\hline \multicolumn{6}{|c|}{ Strip Center } \\
\hline & Car & Transit & Bike & Walk & $\mathrm{p}$-value \\
\hline $\mathrm{N}$ & 1,133 & 11 & 148 & 80 & - \\
\hline Mean age & 51.7 & 62.3 & 46.9 & 46.5 & 0.000 \\
\hline Female & $54.0 \%$ & $81.8 \%$ & $49.3 \%$ & $57.5 \%$ & 0.163 \\
\hline Mean household income ${ }^{1}$ & $\$ 93,504$ & $\$ 26,591$ & $\$ 82,128$ & $\$ 70,656$ & 0.000 \\
\hline Education $^{2}$ & & & & & 0.053 \\
\hline High school or less & $1.2 \%$ & $10.0 \%$ & $1.4 \%$ & $0 \%$ & - \\
\hline Some college & $8.2 \%$ & $10.0 \%$ & $4.8 \%$ & $3.8 \%$ & - \\
\hline Associate's degree & $4.5 \%$ & $0 \%$ & $6.2 \%$ & $3.8 \%$ & - \\
\hline Bachelor's degree & $35.6 \%$ & $30.0 \%$ & $30.3 \%$ & $36.7 \%$ & - \\
\hline Graduate degree(s) & $50.4 \%$ & $50.0 \%$ & $57.2 \%$ & $55.7 \%$ & - \\
\hline \multicolumn{6}{|c|}{ Target } \\
\hline & Car & Transit & Bike & Walk & $\mathrm{p}$-value \\
\hline $\mathrm{N}$ & 620 & 4 & 30 & 8 & - \\
\hline Mean age & 50.9 & 55 & 48.1 & 43.1 & 0.160 \\
\hline Female & $57.4 \%$ & $75.0 \%$ & $43.3 \%$ & $50.0 \%$ & 0.391 \\
\hline Mean household income ${ }^{1}$ & $\$ 91,758$ & $\$ 15,000$ & $\$ 88,333$ & $\$ 70,625$ & 0.055 \\
\hline Education $^{2}$ & & & & & 0.134 \\
\hline High school or less & $1.2 \%$ & $33.3 \%$ & $3.3 \%$ & $0 \%$ & - \\
\hline Some college & $8.7 \%$ & $33.3 \%$ & $10.0 \%$ & $0 \%$ & - \\
\hline Associate's degree & $5.4 \%$ & $0 \%$ & $6.7 \%$ & $0 \%$ & - \\
\hline Bachelor's degree & $35.0 \%$ & $0 \%$ & $50.0 \%$ & $57.1 \%$ & - \\
\hline Graduate degree $(s)$ & $49.7 \%$ & $33.3 \%$ & $30.0 \%$ & $42.9 \%$ & - \\
\hline
\end{tabular}

${ }^{1}$ Survey sample incomes are based on midpoint values of five categorical ranges; for those reporting incomes greater than $\$ 125,000$, an average of $\$ 150,000$ was assumed

${ }^{2}$ Education levels were based on sample aged 25 and over to be comparable to census data for Davis

${ }^{3}$ p-values are for an ANOVA for age, income, and education and chi-squared test of independence for percent female

\subsubsection{Perceptions of the built environment by mode and shopping destination type}

Table 8 displays the perceived convenience of using each mode by the shopper's mode and destination. With the exception of driving and parking, all perceived built environment qualities vary significantly across modes at each destination, with bicyclists and walkers consistently rating cycling and walking as more convenient than drivers or transit users. These differences highlight the importance of controlling for individual perceptions, rather than including only a single measure of observable built environment characteristics. 
Table 8: Average perceptions of the built environment at shopping destinations, by mode

\begin{tabular}{|c|c|c|c|c|c|c|c|}
\hline & \multirow[b]{2}{*}{ Mean $^{1}$} & \multicolumn{4}{|c|}{ Mode used for last shopping trip at this destination } & \multirow{2}{*}{\multicolumn{2}{|c|}{ p-value ${ }^{2}$}} \\
\hline & & Car & Transit & Bike & Walk & & \\
\hline \multicolumn{8}{|l|}{ Downtown } \\
\hline Driving there & 0.773 & 0.777 & 0.643 & 0.613 & 0.676 & 0.090 & $\cdot$ \\
\hline Parking there & -0.282 & -0.275 & -0.214 & -0.214 & -0.319 & 0.762 & \\
\hline Walking there & 0.073 & -0.277 & 0.400 & 0.667 & 1.528 & 0.000 & $* * *$ \\
\hline Biking there & 0.681 & 0.500 & 0.667 & 1.668 & 1.492 & 0.000 & $* * *$ \\
\hline $\begin{array}{l}\text { Quality/availability of } \\
\text { bike parking }\end{array}$ & 0.698 & 0.650 & 0.467 & 1.060 & 0.894 & 0.000 & $* * *$ \\
\hline \multicolumn{8}{|l|}{ Strip Center } \\
\hline Driving there & 1.233 & 1.300 & 1.222 & 1.270 & 1.298 & 0.752 & \\
\hline Parking there & 1.203 & 1.275 & 1.125 & 1.240 & 1.214 & 0.451 & \\
\hline Walking there & -0.431 & -0.533 & 0.000 & 0.113 & 0.902 & 0.000 & $* * *$ \\
\hline Biking there & 0.308 & 0.191 & 0.167 & 1.331 & 1.026 & 0.000 & $* * *$ \\
\hline $\begin{array}{l}\text { Quality/availability of } \\
\text { bike parking }\end{array}$ & 0.601 & 0.588 & 0.889 & 0.993 & 0.962 & 0.000 & $* * *$ \\
\hline \multicolumn{8}{|l|}{ Target } \\
\hline Driving there & 1.249 & 1.279 & 1.000 & 1.394 & 1.700 & 0.253 & \\
\hline Parking there & 1.630 & 1.638 & 1.571 & 1.750 & 1.900 & 0.191 & \\
\hline Walking there & -1.214 & -1.288 & -1.333 & -0.048 & 1.600 & 0.000 & $* * *$ \\
\hline Biking there & -0.401 & -0.484 & -0.600 & 1.057 & 1.375 & 0.000 & $* * *$ \\
\hline $\begin{array}{l}\text { Quality/availability of } \\
\text { bike parking }\end{array}$ & 0.870 & 0.849 & 0.857 & 1.286 & 1.250 & 0.021 & * \\
\hline
\end{tabular}

Mean values for each category are significantly different across destination types, with downtown being the most bicycle and pedestrian friendly and least convenient for driving and parking (first column of Table 8). In general, Target is considered the least bike and pedestrian friendly, consistent with the lower active travel mode shares reported to this destination. Respondents rated Target's bike parking higher than downtown's - perhaps because one is more likely to find an available spot at Target-but this convenience is overshadowed by the perceived convenience of car parking. Importantly, the convenience of walking or biking to any destination is open to the interpretation of the respondent and likely reflects the distance to the store as well as the quality of the street network between the respondent's house and the shopping destination, making it difficult to isolate the precise elements of the built environment that would most encourage walking or biking and underscoring the need to include both observed and perceived characteristics of the built environment.

\subsubsection{Binary logit models for using active travels modes to shop}

To identify key factors associated with the various travel modes across different types of shopping destinations, we estimate binary logit models (Tables 9-11) for each destination. The dependent variable for the model is the use of an active travel mode (walk or bike) to shop, with car as the base mode. While sometimes classified as an active travel mode, transit is excluded from the models because sociodemographic characteristics are significantly different between transit riders and active travel users (Table 7), thus confounding the explanatory power of certain variables. We run three models for each destina- 
tion to see how much explanatory power each set of variables contributes and how their effects vary across destination types. The first model includes only socio-demographic characteristics, the second model adds perceptions of the built environment, and the third model includes attitudes. For all destination types, the most robust models include both perceptions of the built environment and attitudes, though the relative increase in explanatory power varies by destination type.

Table 9: Binary logit models for using active travel modes to shop downtown

\begin{tabular}{|c|c|c|c|c|c|c|c|c|c|c|c|c|}
\hline & \multicolumn{4}{|c|}{ Model \#1 } & \multicolumn{4}{|c|}{ Model \#2 } & \multicolumn{4}{|c|}{ Model \#3 } \\
\hline & Est. & $\begin{array}{l}\text { Std. } \\
\text { Error }\end{array}$ & $\begin{array}{l}\text { Odds } \\
\text { ratio }\end{array}$ & & Est. & $\begin{array}{l}\text { Std. } \\
\text { Error }\end{array}$ & $\begin{array}{l}\text { Odds } \\
\text { ratio }\end{array}$ & & Est. & $\begin{array}{l}\text { Std. } \\
\text { Error }\end{array}$ & $\begin{array}{l}\text { Odds } \\
\text { ratio }\end{array}$ & \\
\hline \multirow{2}{*}{\multicolumn{13}{|c|}{ Socio-demographic }} \\
\hline & & & & & & & & & & & & \\
\hline Age & -0.245 & 0.116 & 0.78 & $*$ & -0.035 & 0.130 & 0.97 & & 0.053 & 0.149 & 1.05 & \\
\hline Male & 0.256 & 0.173 & 1.29 & & 0.105 & 0.184 & 1.11 & & -0.064 & 0.207 & 0.94 & \\
\hline Household income & -0.152 & 0.070 & 0.86 & * & -0.203 & 0.073 & 0.82 & $* *$ & -0.227 & 0.083 & 0.80 & ** \\
\hline Children in household & -0.438 & 0.201 & 0.65 & $*$ & -0.341 & 0.214 & 0.71 & & -0.572 & 0.241 & 0.56 & $*$ \\
\hline Student & -0.910 & 0.312 & 0.40 & $* *$ & -0.908 & 0.328 & 0.40 & $* *$ & -0.731 & 0.359 & 0.48 & * \\
\hline Distance to store & -0.866 & 0.109 & 0.42 & $* * *$ & -0.606 & 0.116 & 0.56 & $* * *$ & -0.625 & 0.128 & 0.54 & $* * *$ \\
\hline Works in Davis & 0.550 & 0.176 & 1.73 & $* *$ & 0.496 & 0.187 & 1.64 & $* *$ & 0.470 & 0.209 & 1.60 & * \\
\hline Time lived in Davis & -0.137 & 0.101 & 0.87 & & -0.160 & 0.108 & 0.85 & & -0.187 & 0.117 & 0.83 & \\
\hline Level of car access & -0.347 & 0.010 & 0.71 & $* * *$ & -0.333 & 0.108 & 0.72 & $* *$ & -0.314 & 0.120 & 0.73 & ** \\
\hline \multicolumn{13}{|l|}{ Built Environment } \\
\hline Driving there & - & - & - & - & -0.368 & 0.092 & 0.69 & $* * *$ & -0.323 & 0.100 & 0.72 & $* *$ \\
\hline Parking there & - & - & - & - & 0.109 & 0.091 & 1.10 & & 0.058 & 0.101 & 1.06 & \\
\hline Walking there & - & - & - & - & 0.078 & 0.082 & 1.09 & & 0.069 & 0.088 & 1.07 & \\
\hline Biking there & - & - & - & - & 0.964 & 0.137 & 2.62 & $* * *$ & 0.504 & 0.143 & 1.65 & $* * *$ \\
\hline $\begin{array}{r}\text { Quality/availability of } \\
\text { bike parking }\end{array}$ & - & - & - & - & -0.057 & 0.093 & 0.95 & & -0.059 & 0.101 & 0.94 & \\
\hline \multicolumn{13}{|l|}{ Attitudes } \\
\hline Enjoys biking & - & - & - & - & - & - & - & - & 1.687 & 0.176 & 5.41 & $* * *$ \\
\hline Prefers to buy local & - & - & - & - & - & - & - & - & 0.192 & 0.174 & 1.21 & \\
\hline Eco concern & - & - & - & - & - & - & - & - & 0.023 & 0.117 & 1.02 & \\
\hline Pro-Target & - & - & - & - & - & - & - & - & 0.045 & 0.123 & 1.05 & \\
\hline \multicolumn{13}{|c|}{ Model Summary } \\
\hline$N$ & \multicolumn{12}{|c|}{1,128} \\
\hline Log likelihood (EL) & \multicolumn{12}{|c|}{-781.82} \\
\hline Log likelihood (MS) & \multicolumn{12}{|c|}{-530.15} \\
\hline Log likelihood (model) & \multicolumn{4}{|c|}{-448.32} & \multicolumn{4}{|c|}{-395.77} & \multicolumn{4}{|c|}{-326.63} \\
\hline Rho-Squared (EL base) & \multicolumn{4}{|c|}{0.43} & \multicolumn{4}{|c|}{0.49} & \multicolumn{4}{|c|}{0.58} \\
\hline Rho-Squared (MS base) & \multicolumn{4}{|c|}{0.15} & \multicolumn{4}{|c|}{0.25} & \multicolumn{4}{|c|}{0.38} \\
\hline $\begin{array}{l}\text { Adjusted Rho-Squared } \\
\text { (EL base) }\end{array}$ & \multicolumn{4}{|c|}{0.41} & \multicolumn{4}{|c|}{0.47} & \multicolumn{4}{|c|}{0.56} \\
\hline
\end{tabular}

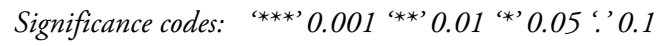

Though different factors explain the choice to use active travel modes to the different destinations, some variables are consistent across destination types. In contrast to previous studies, our results show that age and gender are not important predictors of using active travel modes at any destination type. Length of time lived in Davis has little impact on the use of active travel modes, suggesting that individuals do not make large modal shifts from motorized to non-motorized modes simply by being exposed to higher levels of active travel over time. Surprisingly, both perceived bicycle and car parking convenience 
are insignificant in our model. Attitudes, however, play a role in shopping mode choice; enjoying biking is the single largest determinant in an individual's use of an active travel mode at all destination types.

Most socio-demographic variables remain important with the addition of built environment characteristics and attitudes for downtown travelers. The presence of children under 16 in the household is negatively correlated with active travel modes to downtown. Individuals who work in Davis are more likely to bike or walk to shop downtown, though not to other destinations. This is likely because 40.6 percent of Davis jobs are at the University of California, Davis, situated next to downtown (City of Davis 2012); however, we do not have information about where individual respondents work. Students are less likely to bike or walk downtown, perhaps because they have free access to the university's shuttle system. Not surprisingly, perceived convenience of driving downtown is negatively associated with the use of active travel models, while perceived convenience of bicycling is positively associated with it. While many factors influence active travel to downtown, the most important predictor is an enjoyment of bicycling; other attitudes do not play an important role. Respondents without strong environmental concerns also use active travel modes to shop downtown, suggesting that the downtown shopping experience is more amenable to biking and walking, or that the inconvenience of driving downtown is strong enough to deter even those without a predisposition toward cycling from driving.

In contrast to the results for downtown, income, student status, and having children are not good predictors of using active travel modes to shop at strip centers. After cycling enjoyment, car access and distance are the most important determinants of biking and walking to shop. Individuals who work in Davis are more likely to use active travel modes, though the effect is insignificant after controlling for attitudes. Predictably, the farther away a respondent lives from her or his shopping destination, the less likely she or he is to bike or walk. 
Table 10: Binary logit models for using active travel modes to shop at strip centers

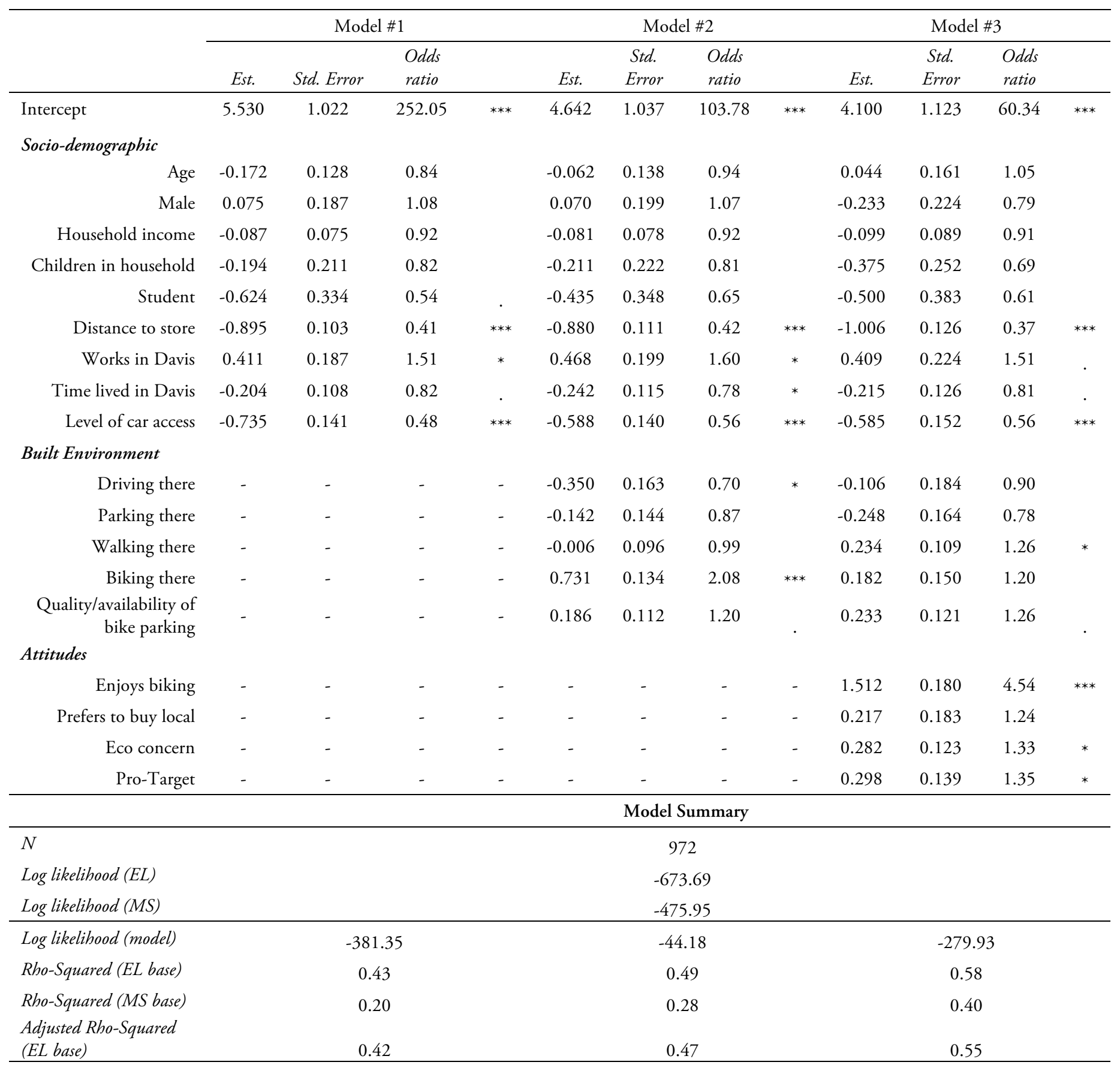

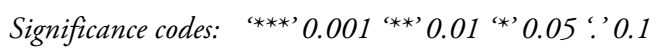


Table 11: Binary logit models for using active travel modes to shop at Target

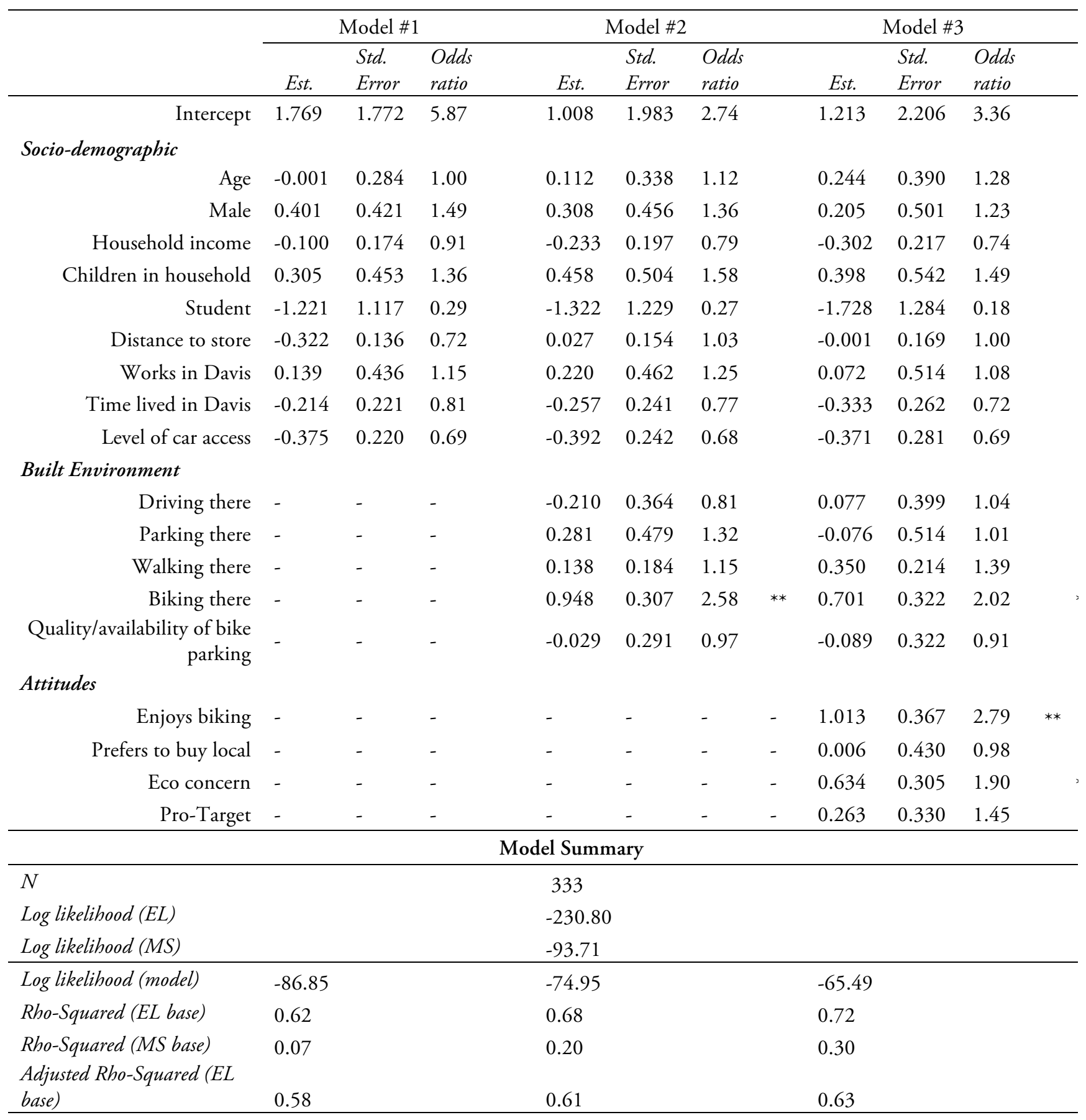

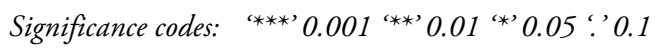

In contrast to downtown, concern for the environment does play a role in the choice to bike or walk to Target and strip centers, suggesting that individuals with environmental preferences may go out of their way to bike or walk to shopping destinations even if they are farther away. At Target, neither sociodemographic characteristics nor perceptions of the built environment explain the choice to bike or walk. The key factors are perceived bicycling convenience, enjoyment of bicycling, and eco concern. 
Different factors help to explain the choice to take active travel modes to the different shopping destinations. Respondents who biked to shop are more likely to perceive each shopping destination as convenient for cycling, underscoring the importance of individual perceptions of active travel amenities. However, the provision of parking - for bikes or for cars — does not have a significant influence on mode to any destination type. While the magnitude and significance of different factors vary greatly across the destination types (indicating that the shopping destinations do have observable and important differences), these differences cannot be attributed to specific elements of the built environment without more information. This result suggests that-while the characteristics of the shopping environment play a role in the decision to bike or walk to shop-attitudes are a better predictor of mode choice.

\subsection{Factors associated with greater individual use of bicycling for shopping trips}

We can exploit the multi-modal travel behavior of our sample (Table 6) to better understand why an individual might bike to one shopping destination and not another. Ordered logit models identify individual-level factors that might help explain how many of the respondent's most recent shopping trips to each destination type were completed by bicycle (Table 12). The first model considers the number of shopping trips completed by bike to the two different destination types when Target was not yet an option (downtown and strip centers), with values ranging from zero to two bike trips. The second model considers the number of bicycling trips in the second year, after Target opened. Models were run using the cumulative ordered logit specification, which categorizes individuals based on the cumulative probability of being in one category (e.g., no bike trips) or the next (e.g., one bike trip). We used a proportional odds approach, which assumes that impacts increase at a relatively constant rate from one category to the next. Built environment characteristics are not included in these models because they vary by destination type.

${ }^{1}$ To test the validity of the proportional odds approach, we first allowed the parameter estimates to vary by category and then ran the models in parallel form to verify that the coefficient estimates in the unrestricted models were similar to those of the parallel model for all variables. For parsimony and ease of interpretation, the parallel specifications are presented here. 
Table 12: Ordered logit models for number of most recent shopping trips completed by bicycle

\begin{tabular}{|c|c|c|c|c|c|c|}
\hline & \multicolumn{2}{|c|}{ Before Target (2009) } & & \multicolumn{3}{|c|}{ After Target (2010) } \\
\hline & Estimate & Std. Error & & Estimate & Std. Error & \\
\hline Intercept (some trips) & -0.521 & 0.957 & & 1.128 & 1.314 & \\
\hline Intercept (all trips) & -2.325 & 0.966 & $*$ & -1.869 & 1.333 & \\
\hline \multicolumn{7}{|l|}{ Socio-demographic } \\
\hline Age & -0.017 & 0.010 & . & 0.012 & 0.014 & \\
\hline Male & 0.148 & 0.236 & & -0.092 & 0.324 & \\
\hline Children in household & -0.782 & 0.279 & ** & -0.962 & 0.352 & $* *$ \\
\hline Household income & -0.061 & 0.094 & & -0.077 & 0.137 & \\
\hline Student (part- or full-time) & -0.736 & 0.409 & ${ }^{\circ}$ & -0.780 & 0.645 & \\
\hline Level of car access & -0.192 & 0.123 & & -0.260 & 0.185 & \\
\hline Time lived in Davis & -0.046 & 0.132 & & -0.431 & 0.184 & * \\
\hline Works in Davis & 0.259 & 0.237 & & 0.320 & 0.328 & \\
\hline \multicolumn{7}{|l|}{ Attitudes } \\
\hline Enjoys biking & 2.250 & 0.209 & $* * *$ & 1.765 & 0.252 & $* * *$ \\
\hline Prefers to buy local & 0.257 & 0.190 & & 0.161 & 0.284 & \\
\hline Eco concern & 0.057 & 0.128 & & 0.211 & 0.184 & \\
\hline Pro-Target & - & - & & 0.001 & 0.212 & \\
\hline \multicolumn{7}{|c|}{ Model Summary } \\
\hline$N$ & & 702 & & & 355 & \\
\hline Log likelihood (EL) & & -771.23 & & & -390.01 & \\
\hline Log likelihood (MS) & & -411.77 & & & -201.12 & \\
\hline Log likelihood (model) & & -288.68 & & & -147.53 & \\
\hline Rho-Squared (EL base) & & 0.63 & & & 0.62 & \\
\hline Adjusted Rho-Squared (EL) & & 0.61 & & & 0.59 & \\
\hline Rho-Squared (MS base) & & 0.30 & & & 0.27 & \\
\hline Adjusted Rho-Squared (MS base) & & 0.27 & & & 0.21 & \\
\hline
\end{tabular}

Consistent with the binary logit results (Tables 9-11), few individual characteristics have a significant impact on bicycling trips to shopping destinations. Importantly, though the samples are comprised of mostly different individuals for each year, there is little variation in the impacts of the various factors across the two years. Most of the standard socio-demographic variables that have been correlated with bicycling in previous research (e.g. young, male, high income) are not significant determinants of an individual's number of bicycling trips in our sample (Table 12). The lack of significance of these variables suggests that a broad cross-section of Davis residents use multiple travel modes and that differences in bicycling frequency are not well explained by individual socio-demographic characteristics. As expected, people who enjoy bicycling are more likely to make more shopping trips by bike. Respondents with children are less likely to bike for all of their shopping trips.

While shopping mode choice may be influenced by perceptions of the built environment and attitudes, the size and type of purchase are likely important determinants of mode choice as well. However, while we have information about the category of items purchased, we do not know the exact item and cannot therefore control for the size of the purchase. Using trip spending amount as proxy for item size (creating a dummy variable for purchases under \$30) did not significantly impact any model, suggesting that price is either not an adequate proxy for item size or that item size is not a good predictor of mode choice. 


\section{$5 \quad$ Discussion and conclusion}

As municipalities increasingly aim to encourage sustainable travel modes, an understanding of what motivates individuals to choose active travel modes to shop is helpful for policymakers. This study contributes to the growing body of research on mode choice for retail activity by shedding light on the complex way that the built environment influences shopping mode choice. We find that perceptions of broad qualities of the built environment have an influence on mode choice, though their importance varies by destination type. In particular, perceptions of the convenience of bicycling and driving to shopping destinations are important determinants of mode choice. This perceived convenience might represent a host of characteristics that were unaccounted for in the models, including quality of the bike network, macrolevel land uses, neighborhood or shopping center safety, and other innumerable characteristics that might influence an individual's inclination toward cycling or walking. Furthermore, perceptions of the convenience of using different modes to the same destination vary greatly depending on an individual's chosen mode, complicating the notion of using a single measure of the built environment as a predictor of mode choice and underscoring the importance of controlling for perceptions of available modes in addition to measurable elements of the built environment. However, because we have no way of knowing how a respondent interpreted "bicycling convenience" in this study, we cannot make a direct link from these perceptions to the impacts of specific infrastructure changes on mode choice.

Similarly, while the differences in magnitudes and significance of factors in the logit models indicate that there is something intrinsically different between the shopping destination types, these differences cannot be attributed to particular elements of the shopping destinations themselves (e.g., bike parking). Contrary to findings from prior research (Handy and Clifton 2010; Jiao, Moudon, and Drewnowski 2011), perceptions of bicycle and car parking convenience are not significant predictors of active travel use in our sample. Thus, destination-based infrastructure changes like increased bicycle parking are probably not sufficient to encourage mode shift. On the other hand, the relative inconvenience of driving to downtown is positively associated with walking and biking to this destination, and by making vehicle parking more difficult at other shopping destinations, alternative modes could become more appealing.

Perhaps because a number of individuals use different modes to get to different shopping destinations, socio-demographic characteristics are not as important determinants of mode choice in our sample as in prior research. On the other hand, attitudes toward cycling and the environment are important to mode choice, though their impacts also vary across shopping destinations. Enjoyment of bicycling is the most important factor for choosing active travel modes for all destination types. While this result is consistent with findings from previous studies in Davis and other cities (Handy, Xing, and Buehler 2010; Heinen and Handy 2012), it makes it more difficult to tease out how changes to the built environment would influence mode choice to any specific destination type.

Davis is a unique place to study such consumer behavior, and these findings may not be generalizable to many contexts. Further analysis is needed to determine whether this pattern holds in other situations. In particular, this study focused on a limited set of goods and on the most recent trip to each destination. A survey that included a complete diary of shopping trips over an extended period of time would provide a clearer picture of the connection between destination type and mode choice but would be extremely difficult to implement. Incorporating environmental attitudes into mode choice surveys could help validate the measures used in this study and also identify which specific environmental preferences or behaviors are the strongest predictors of travel behavior. In addition, while other studies have demonstrated that infrastructure influences mode choice to shopping destinations (Bent and Singa 2009; O'Connor et al. 2011; Fleming, Turner, and Tarjomi 2013; McCormick 2012; Meisel 2010; Jiao, Moudon, and Drewnowski 2011), before-and-after studies would provide more definitive evidence on the impact of improved bike infrastructure on mode choice. In Davis, where nearly all respondents are within 50 meters of a bike lane or bike path, the impact of access to cycling infrastructure is hard to model. In future studies, an analysis of the quality of cycling infrastructure-e.g., links to bike paths from residential locations and shopping destinations-could aid in this endeavor. 


\section{Acknowledgements}

This study was funded by grants from the UC Davis Sustainable Transportation Center, supported by the U.S. Department of Transportation and the California Department of Transportation (Caltrans) through the University Transportation Centers program; the Sustainable Transport Program funded by UC Multicampus Research Programs and Initiatives; the Hewlett Foundation; and AAA.

\section{References}

American Community Survey 2012

URL: http://www.census.gov/acs/www/data_documentation/data_main/

Bent, E., and K. Singa. 2009. Modal choices and spending patterns of travelers to downtown San Francisco, California. Transportation Research Record 2115: 66-74.

http://trb.metapress.com/content/1668640620x82m24/fulltext.pdf.

Buehler, T., and S. Handy. 2008. Fifty years of bicycle policy in Davis, CA. Transportation Research Record 2074: 52-57. URL: http://trb.metapress.com/content/nml846273861qg18/fulltext.pdf.

Cervero, R., and R. Gorham. 1995. Commuting in transit versus automobile neighborhoods. Journal of the American planning Association, 61(2): 210-225.

http://www.tandfonline.com/doi/pdf/10.1080/01944369508975634\#.U-vAFlbyuBk.

City of Davis. 2012. City of Davis Comprehensive Annual Financial Report for the Fiscal Year Ended June

30, 2012.

http://administrativeservices.cityofdavis.org/Media/Default/Documents/PDF/Finance/CAFR-

Documents/Davis2012CAFR-RDA.pdf.

Clifton, K., C. Muhs, S. Morrissey, T. Morrissey, K. Currans, and C. Ritter. 2013. Examining Consumer Behavior and Travel Choices (No. OTREC-RR-12-15). http://ntl.bts.gov/lib/47000/47000/47039/OTREC-RR-12-15_Final.pdf.

Clifton, K., S. Morrissey, and C. Ritter. 2012. Mode choice and consumer spending: An examination of grocery store trips. In 91st Annual Meeting of the Transportation Research Board, January 22-26, Washington, DC. http://otrec.us/files/OTS2012_Morrissey-Poster.pdf.

Driller, B. 2013 Results of 2012-13 Campus Travel Survey. Institute of Transportation Studies, University of California, Davis, Research Report UCD-ITS-RR-13-18. URL:

http://www.its.ucdavis.edu/research/publications/publication-detail/?pub_id=1962.

Ewing, R., and R. Cervero. 2010. Travel and the built environment: a meta-analysis. Journal of the American Planning Association 76(3): 265-294.

http://mw8xt6bj7r.search.serialssolutions.com/?genre=article\&issn=01944363\&title=Journal +of +the+ Amercan + Planning + Association \&volume $=76 \&$ issue $=3 \&$ date $=20100601 \&$ atitle $=$ Travel + and + the + Bui lt + Environment. \&spage= 265\&pages=265294\&sid=EBSCO:Academic + Search + Premier\&au $=$ Ewing $\% 2 c+$ Reid.

Fleming, T., S. Turner, and L. Tarjomi. 2013. Research report 530-Reallocation of road space. http://www.nzta.govt.nz/resources/research/reports/530/docs/RR-530-Reallocation-of-roadspace.pdf.

Frank, L., and G. Pivo. 1994. Impacts of mixed use and density on utilization of three modes of travel: Single-occupant vehicle, transit, and walking. Transportation Research Record 1466: 44-52. http://www.reconnectingamerica.org/assets/Uploads/Frank-and-Pivo.pdf.

Handy, S. 1996. Understanding the link between urban form and nonwork travel behavior. Journal of Planning Education and Research 15: 183-198. http://jpe.sagepub.com/content/15/3/183.abstract.

Handy, S., and K. Clifton. 2001. Local shopping as a strategy for reducing automobile travel. Transportation 28(4): 317-346. URL: http://www.des.ucdavis.edu/faculty/handy/handy_and_clifton.pdf 
Handy, S., Y. Xing, and T. Buehler. 2010. Factors associated with bicycle ownership and use: A study of six small US cities. Transportation 37(6): 967-985. http://link.springer.com/article/10.1007/s11116010-9269-x/fulltext.html

Heinen, E., and S. Handy. 2012. Similarities in attitudes and norms and the effect on bicycle commuting: Evidence from the bicycle cities Davis and Delft. International Journal of Sustainable Transportation, 6(5): 257-281. http://www.tandfonline.com/doi/full/10.1080/15568318.2011.593695\#.VAtMNWRdWTQ

Heinen, E., K. Maat, and B. Wee. 2011. The role of attitudes toward characteristics of bicycle commuting on the choice to cycle to work over various distances. Transportation Research Part D: Transport and Environment, 16(2): 102-109.

http://www.sciencedirect.com/science/article/pii/S1361920910001306

Jiao, J., A. Moudon, and A. Drewnowski. 2011. Grocery shopping. Transportation Research Record 2230(1): 85-95. URL: http://depts.washington.edu/uwcphn/pubs/author/docs/Jiao_2011.pdf

Lovejoy, K., G. Sciara, D. Salon, S. Handy, and P. Mokhtarian. 2013. Measuring the impacts of local land-use policies on vehicle miles of travel: The case of the first big-box store in Davis, California. Journal of Transport and Land Use 6(1): 25-39. https://www.jtlu.org/index.php/jtlu/article/view/336/300.

McCormick, C. 2012. York Boulevard: The economics of a road diet. Unpublished. http://la.streetsblog.org/wp-content/pdf/york_blvd_final_report_compress.pdf.

Meisel, D. 2010 Bike Corrals: Local Business Impacts, Benefits, and Attitudes. Portland, OR: School of Urban Studies and Planning, Portland State University. http://bikeportland.org/wpcontent/uploads/2010/05/PDX_Bike_Corral_Study.pdf.

O'Connor, D., J. Nix, S. Bradshaw, and E. Shiel. 2011. Shopping travel behavior in Dublin city center. Presented at the ITRN Conference, Aug. 30-Sept. 1, Cork, Ireland. http://arrow.dit.ie/comlinkoth/10/.

Rodriguez, D., and J. Joo. 2004. The relationship between non-motorized mode choice and the local physical environment. Transportation Research Part D: Transport and Environment, 9(2): 151-173. http://www.sciencedirect.com/science/article/pii/S1361920903000889.

Santos, A., N. McGuckin, H.Nakamoto, D. Gray, and S. Liss. 2011. Summary of Travel Trends: 2009 National Household Travel Survey. FHWA-PL-11-022. Washington, DC: Federal Highway Administration, U.S. Department of Transportation. http://nhts.ornl.gov/2009/pub/stt.pdf.

Schneider, R. J., and S. Pande. 2012. How common is pedestrian travel to, from, and within shopping districts? Transportation Research Record 2299(1): 11-21. http://escholarship.org/uc/item/1pb9v7xq\#page-1.

Schwanen, T., and P. Mokhtarian. 2005. What affects commute mode choice: Neighborhood physical structure or preferences toward neighborhoods? Journal of Transport Geography, 13(1): 83-99. http://www.uctc.net/papers/732.pdf.

Shiftan, Y., and Y. Barlach. 2002. Effect of employment site characteristics on commute mode choice. Transportation Research Record 1781(1): 19-25.

https://trb.metapress.com/content/c79302g54r7414q9/resource-secured/?target=fulltext.pdf.

Transportation Alternatives. 2012. East Village Shopping Survey: A Snapshot of Travel and Spending Patterns of Residents and Visitors in the East Village. http://transalt.org/files/news/reports/2012/EVSS_Final.pdf.

Vredin Johansson, M., T. Heldt, and P. Johansson. 2006. The effects of attitudes and personality traits on mode choice. Transportation Research Part A: Policy and Practice, 40(6): 507-525. http://www.sciencedirect.com/science/article/pii/S0965856405001473. 